\title{
In Vitro Effect of Acidic Challenges on the Physical Properties of Dental Prosthesis Artificial Teeth
}

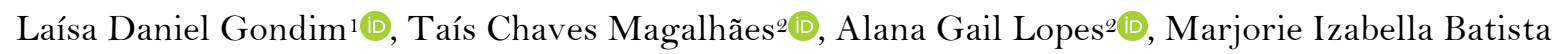

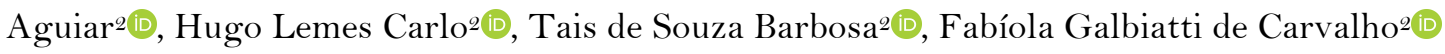

${ }^{1}$ Department of Operative Dentistry, Federal University of Paraíba, João Pessoa, PB, Brazil.

2Department of Dentistry, Federal University of Juiz de Fora, Governador Valadares Campus, Governador Valadares, MG, Brazil.

Author to whom correspondence should be addressed: Profa. Fabíola Galbiatti de Carvalho, Universidade Federal de Juiz de Fora, Campus Governador Valadares, Departamento de Odontologia, Av. Dr. Raimundo Monteiro de Rezende, $\mathrm{n}^{\circ} 330$, Sala 301, Centro, Governador Valadares, MG, Brazil. 35010-177. Phone: +55 3333011000, extension line 1580. E-mail: fabigalbi@yahoo.com.br.

Academic Editors: Alessandro Leite Cavalcanti and Wilton Wilney Nascimento Padilha

Received: 31 October 2019 / Accepted: 28 April 2020 / Published: 26 May 2020

How to cite this article: Gondim LD, Magalhães TC, Lopes AG, Aguiar MIB, Carlo HL, Barbosa TS, et al. In vitro effect of acidic challenges on the physical properties of dental prosthesis artificial teeth. Pesqui Bras Odontopediatria Clín Integr. 2020; 20:e5365. https://doi.org/10.1590/pboci.2020.091

\begin{abstract}
Objective: To evaluate the effect of immersion and acid challenge with cola drink on color change $(\Delta \mathrm{E})$, Vickers hardness (VHN) and surface roughness (Ra) of artificial acrylic resin teeth. Material and Methods: The artificial teeth were divided into 6 groups $(\mathrm{n}=8)$ : TC (Trilux/Control), BC (Biotone/Control), TAC (Trilux/Acid challenge), BAC (Biotone/Acid challenge), TI (Trilux/Immersion) and BI (Biotone/Immersion). The teeth were embedded in acrylic resin and the labial side was serially polished to provide appropriate flat surface. The samples of TC, BC, TI, BI groups were immersed in artificial saliva and cola drink (coke) for 7 days, respectively. The acid challenge was performed with immersion of samples in coke for $5 \mathrm{~min}$, and subsequently immersion in artificial saliva for $2 \mathrm{~h}$. This cycle was repeated at 4 times/day, during 7 days. The tests of VHN, $\Delta \mathrm{E}$ and Ra were analyzed before and after the challenge and immersion groups. Data was analyzed by ANOVA, Tukey and T test $(\alpha=0.05)$. Results: There was no difference in $\mathrm{Ra}$ values between groups after treatments. However, there was a decrease in VHN for all groups. BI (19.2 \pm 0.3$)$ presented significantly lower hardness than BAC $(19.5 \pm 0.9)$ and $\mathrm{BC}(20.2 \pm 0.5)$. Groups BI $(2.18 \pm 0.41)$ and TI $(1.50 \pm 0.43)$ had statistically higher $\Delta \mathrm{E}$ compared to the other groups. Conclusion: The hardness of resin teeth decreased after acid challenges, but the roughness surface was not affected. The color was more affected by the times of exposure in cola beverage and remineralization in artificial saliva, which were associated to the material degradation.
\end{abstract}

Keywords: Acrylic Resins; Tooth, Artificial; Dental Prosthesis; Hardness; Tooth Erosion. 


\section{Introduction}

The treatment of partial or total removable dentures is still one of the most accomplished treatments for oral rehabilitation [1]. The longevity of dental prosthesis varies between 10 and 20 years, given that in the first 10 years it is possible to find wear in about $50 \%$ of the prosthetic structure [2]. Among the structures of dental prosthesis, it was demonstrated that the wear resistance of the artificial teeth is directly related to the prosthesis useful time [3]. Thus, the evaluation of the artificial teeth physical properties is extremely important for clinical practice, in order to predict their durability and interference in the aesthetics of the prosthesis $[4,5]$.

The acrylic resin artificial teeth are widely used in dentures due to the easy occlusal adjustment, lower fractures propensity compared to ceramic, excellent chemical bonding with the base of the prosthesis and adequate absorption of masticatory forces [4,6-8].

During the clinical use, the acrylic artificial teeth are exposed to saliva, cleaning agents and beverages, which favors the chemical absorption and adsorption processes [7]. In this context, acidic beverages deserve special attention since their consumption can contribute to the development of corrosion in artificial teeth [9].

Corrosion in the oral cavity is considered the chronic loss of mineralized dental tissues and chemical attack of dental materials structure due to the chemical degradation of the surface by acid agents or chelating agents, without bacterial involvement [10,11]. The effect of beverages on the artificial teeth may change the hardness and the roughness surface and interfere on the accumulation of biofilm and on the optical properties of the material, affecting the quality of the prothesis over years [7,9,12,13]. However, the type of acid beverage, the exposure time and the corrosive challenge with the beverage can affect differently the physical properties of acrylic resin teeth surface [4,7-9].

Thus, the present in vitro study aimed to evaluate the effect of immersion and acid challenge with cola drink on color change $(\Delta \mathrm{E})$, Vickers hardness (VHN) and surface roughness (Ra) of artificial acrylic resin teeth. The null hypothesis tested is that there is no change in the color stability, hardness and roughness of acrylic resin teeth after different treatments on acidic beverage.

\section{Material and Methods}

Specimens Preparation

Forty-eight maxillary central incisors of two trademarks were investigated: Trilux, color A3 (vipi Produtos Odontológicos, Pirassununga, SP, Brazil) and Biotone IPN, color A3 (Dentsply Ind. Com. Ltda. Petrópolis, RJ, Brazil). Maxillary incisors were chosen to provide a sufficient labial area for hardness and roughness tests. The teeth were embedded in acrylic resin and the labial side was serially polished to provide appropriate flat surface areas with 400, 600, 1200 grit silicon carbide abrasive paper coupled to a metallographic polisher, model APL-2 (Arotec S.A. Ind. e Com., Cotia, SP, Brazil) under permanent water cooling. The specimens were then stored in containers of distilled water at $37^{\circ} \mathrm{C}$ for $24 \mathrm{~h}$ and subsequently subjected to initial color, roughness and hardness surface measurements.

Six groups were formed $(n=8)$ according to the type of artificial tooth and the acid challenge (treatment), as follows: TC (Trilux and control immersion); BC (Biotone and control immersion); TAC (Trilux and acid challenge); BAC (Biotone and acid challenge); TI (Trilux and acid immersion) and BI (Biotone and acid immersion).

Acid Challenge and Immersion of Specimens 
The specimens of control groups (TC and BC) were immersed in artificial saliva for 7 days. The artificial saliva was created according to a previous study [14] and renewed every day. The specimens of immersion groups (TI and BI) were immersed in a cola drink (pH 2.3, Coca-Cola Brasil, Rio de Janeiro, RJ, Brazil), using individual containers $(10 \mathrm{~mL} / \mathrm{specimen})$ at room temperature for 7 days, and the beverage was renewed every day.

The specimens of acid challenge (TAC and BAC) were immersed in a cola drink, pH 2.3 (Coca-Cola Brasil, Rio de Janeiro, RJ, Brazil), using individual containers (10 mL/specimen) at room temperature, for 5 min, subsequently, the specimens were rinsed thoroughly with distilled water and immersed in artificial saliva, at a $\mathrm{pH}$ of $7.0(10 \mathrm{~mL} / \mathrm{block})$ at room temperature for $2 \mathrm{~h}$, this cycle was repeated at 4 times/day $[15,16]$. After the last cycle, samples were rinsed with distilled water and immersed in artificial saliva until completing 24 hours [16]. This corrosive challenge was repeated for 7 days. The cola drink and the artificial saliva were changed after every cycle ( $5 \mathrm{~min}$ in cola drink and $2 \mathrm{~h}$ in artificial saliva). During the acidic cycles, the samples were kept in hermetically sealed containers to prevent the loss of carbonation from the cola drink. At the end of the acid challenge and immersions, the specimens were ultrasonically washed for $10 \mathrm{~min}$ and dried with absorbent paper.

\section{Color Variation, Roughness and Hardness Measurements}

The analysis of color variation, roughness and hardness surface was performed before and after each treatment. The variation of color was determined with the spectrophotometer (Spectrophotometer Easyshade, VITA Zahnfabrik, BadSäckingen, Germany) according to the Commission Internationale de l'Eclairage (CIE) $\mathrm{L}^{*} \mathrm{a}^{*} \mathrm{~b}^{*}$ system. This consists of two axes, $\mathrm{a}^{*}$ and $\mathrm{b}^{*}$, that have right angles and represent the dimension of tonality or color. The third axis is luminosity $\mathrm{L}^{*}$. This is perpendicular to the plane $\mathrm{a}^{*} \mathrm{~b}^{*}$. For color readouts, the test specimens were dried with absorbent paper, and placed on a standard white background. All measurements were repeated twice and the mean for the $\mathrm{L}^{*}, \mathrm{a}^{*}$, and $\mathrm{b}^{*}$ values was calculated. The variation of color on each specimen was determined by the calculation of $\Delta \mathrm{E}$, using the following formula:

$\Delta \mathrm{E}^{*}=\left\{\left(\Delta \mathrm{L}^{*}\right) 2+\left(\Delta \mathrm{a}^{*}\right) 2+\left(\Delta \mathrm{b}^{*}\right) 2\right\} 1 / 2$, where $\Delta \mathrm{L}^{*}=\mathrm{L}^{*} \mathrm{f}-\mathrm{L}^{*} \mathrm{i}, \Delta \mathrm{a}^{*}=\mathrm{a} * \mathrm{f}-\mathrm{a}^{*} \mathrm{i}$ and $\Delta \mathrm{b}^{*}=\mathrm{b}^{*} \mathrm{f}-\mathrm{b}^{*} \mathrm{i} ;$ where $\mathrm{L}^{*} \mathrm{i}, \mathrm{a} * \mathrm{i}$ and $\mathrm{b}^{*} \mathrm{i}$ are referred to as the initial color measurement and $\mathrm{L} * \mathrm{f}, \mathrm{a} * \mathrm{f}$ and $\mathrm{b}^{*} \mathrm{f}$ as the final color measurement. Values of $\Delta \mathrm{E} \geq 3.3$ were considered clinically unacceptable [17].

For the roughness test, the specimens were fitted to the surface roughness-measuring instrument (TR200, Digimess Instrumentos de Precisão Ltda., São Paulo, SP, Brazil) with a cutoff of $0.8 \mathrm{~mm}$ and speed of $0.5 \mathrm{~mm} / \mathrm{s}$, adding up to a measurement path of $2.4 \mathrm{~mm}$ [12,13]. In each specimen, three successive measurements in the central area of teeth labial surface (in different directions) were obtained by the same examiner, and the mean surface roughness values $(\mathrm{Ra})$ were obtained and expressed in micrometers.

The microhardness measurements were performed with a hardness tester (HMV II; Shimadzu Corporation, Kyoto, Japan) using a Vickers indenter (VHN) and a load of $100 \mathrm{~g}$ with a dwell time of $10 \mathrm{~s}$ $[12,13]$. Five indentations were made in the labial area of each specimen, at least $100 \mu \mathrm{m}$ apart, and the mean VHN value was obtained.

\section{Statistical Analysis}

Data analysis was performed with the GraphPad Instat computer program, version 2.0 (GraphPad Software, CA, USA), at a level of significance of $\alpha=0.05$. Because all of the variables tested satisfied the assumptions of normal distribution, one-way ANOVA and Tukey's test were performed for statistical 
comparisons of Ra, VHN and variation of color values among the acid challenges. The paired t-test was used to compare Ra, VHN and variation of color values before and after the acid challenges for the same artificial teeth. The unpaired t-test was used to compare Ra, VHN and variation of color values between artificial teeth in each acid challenge.

\section{Results}

The Table 1 shows the results regarding the analysis of the color variation $(\Delta \mathrm{E})$ after treatments. There was a significant increase of $\Delta \mathrm{E}$ only for Biotone acid immersion group $(\mathrm{BI})(2.18 \pm 0.41)(\mathrm{p}=0.001)$. For BAC and BC groups there was no significant difference $(p=0.07)$. Similarly, in the comparison between teeth groups $(\mathrm{B}$ and $\mathrm{T}$ ) for each treatment, there was a significant difference of $\Delta \mathrm{E}$ only in acid immersion, and $\mathrm{BI}$ group showed higher $\Delta \mathrm{E}(2.18 \pm 0.41)$ compared to TI group $(1.50 \pm 0.43)(\mathrm{p}=0.001)$.

For VHN results, there was no difference among treatments for both artificial teeth groups in each experimental period (initial or after treatments) $(\mathrm{p}=0.07)$ (Table 2). However, there was significant reduction of VHN values after treatments for Biotone and Trilux groups, regardless of the treatment (acid challenge, acid immersion or control) $(\mathrm{p}=0.001)$. There was no significant difference for VHN values between the artificial teeth materials $(B$ and $T)$ in eachtreatment $(\mathrm{p}=0.08)$. Similarly, there was no significant difference for Ra values between artificial teeth tested $(p=0.09)$ and among treatments performed $(p=0.08)$ (Table 3$)$.

Table 1. Mean values of color variation of artificial teeth, obtained from the formula $\Delta \mathrm{E}=$ $\left(\Delta \mathrm{E}^{*}=\left\{\left(\Delta \mathrm{L}^{*}\right) 2+\left(\Delta \mathrm{a}^{*}\right) 2+\left(\Delta \mathrm{b}^{*}\right) 2\right\} 1 / 2\right)$, according to the acid treatments.

\begin{tabular}{cccc} 
Groups & \multicolumn{2}{c}{ Color Variation $(\Delta \mathbf{E})$} & Acid Immersion \\
& Acid Challenge & Mean $(\mathrm{SD})$ & $\begin{array}{c}\text { Control Immersion } \\
\text { Mean }(\mathrm{SD})\end{array}$ \\
\hline Biotone $(\mathrm{B})$ & $1.14 \pm 0.36^{\mathrm{A}, \mathrm{a} \uparrow}$ & $2.18 \pm 0.41^{\mathrm{B}, \mathrm{a}}$ & Mean $(\mathrm{SD})$ \\
Trilux $(\mathrm{T})$ & $1.40 \pm 0.49^{\mathrm{A}, \mathrm{a}}$ & $1.50 \pm 0.43^{\mathrm{A}, \mathrm{b}}$ & $1.34 \pm 0.63^{\mathrm{A}, \mathrm{a}}$ \\
\hline
\end{tabular}

+Same uppercase letters represent values without significant statistical difference among treatments for each artificial tooth ( $\mathrm{p}>0.05$ by ANOVA and Tukey-tests). Same lowercase letters represent values without significant statistical difference between artificial teeth in each treatment $(\mathrm{p}>0.05$ by unpaired T-test)

Table 2. Mean of Vickers hardness (VHN) values of artificial teeth according to the acid treatments and experimental period.

\begin{tabular}{|c|c|c|c|c|c|c|}
\hline \multirow[b]{2}{*}{ Groups } & \multicolumn{3}{|c|}{ VHN Initial } & \multicolumn{3}{|c|}{ VHN After Treatments } \\
\hline & $\begin{array}{c}\text { Acid Challenge } \\
\text { Mean (SD) }\end{array}$ & $\begin{array}{c}\text { Acid Immersion } \\
\text { Mean (SD) }\end{array}$ & $\begin{array}{c}\text { Control } \\
\text { Mean (SD) }\end{array}$ & $\begin{array}{l}\text { Acid Challenge } \\
\text { Mean (SD) }\end{array}$ & $\begin{array}{l}\text { Acid Immersion } \\
\text { Mean (SD) }\end{array}$ & $\begin{array}{c}\text { Control } \\
\text { Mean (SD) }\end{array}$ \\
\hline Biotone (B) & $22.9 \pm 0.5^{\mathrm{A}, \mathrm{a} \uparrow}$ & $21.8 \pm 0.6^{\mathrm{A}, \mathrm{a}}$ & $22.9 \pm 1.0^{\mathrm{A}, \mathrm{a}}$ & $19.5 \pm 0.9^{\mathrm{A}, \mathrm{b}}$ & $19.2 \pm 0.3^{\mathrm{A}, \mathrm{b}}$ & $20.2 \pm 0.5^{\mathrm{A}, \mathrm{b}}$ \\
\hline Trilux $(\mathrm{T})$ & $21.4 \pm 1.2^{\mathrm{A}, \mathrm{a}}$ & $20.8 \pm 0.6^{\mathrm{A}, \mathrm{a}}$ & $21.1 \pm 0.7^{\mathrm{A}, \mathrm{a}}$ & $19.6 \pm 1.1^{\mathrm{A}, \mathrm{b}}$ & $18.7 \pm 0.7^{\mathrm{A}, \mathrm{b}}$ & $19.2 \pm 0.6^{\mathrm{A}, \mathrm{b}}$ \\
\hline
\end{tabular}

Tame uppercase letters represent values without significant statistical difference among treatments for each artificial tooth in each experimental period (initial or after treatments) ( $p>0.05$ by ANOVA and Tukey-tests). Same lowercase letters represent values without significant statistical difference in each treatment for each artificial tooth before and after acid challenges ( $\mathrm{p}>0.05$ by paired $\mathrm{t}$-test).

Table 3. Mean of roughness surface values $(\mathrm{Ra})$ of artificial teeth according to the acid treatments and experimental period.

\begin{tabular}{|c|c|c|c|c|c|c|}
\hline \multirow[b]{2}{*}{ Groups } & \multicolumn{3}{|c|}{ Ra Initial (in micrometers) } & \multicolumn{3}{|c|}{ Ra After Treatment (in micrometers) } \\
\hline & $\begin{array}{c}\text { Acid Challenge } \\
\text { Mean (SD) }\end{array}$ & $\begin{array}{c}\text { Acid Immersion } \\
\text { Mean (SD) }\end{array}$ & $\begin{array}{c}\text { Control } \\
\text { Mean (SD) }\end{array}$ & $\begin{array}{c}\text { Acid Challenge } \\
\text { Mean (SD) }\end{array}$ & $\begin{array}{l}\text { Acid Immersion } \\
\text { Mean (SD) }\end{array}$ & Control \\
\hline Biotone (B) & $0.06 \pm 0.01^{\mathrm{A}, \mathrm{a} \uparrow}$ & $0.07 \pm 0.01^{\mathrm{A}, \mathrm{a}}$ & $0.07 \pm 0.01^{\mathrm{A}, \mathrm{a}}$ & $0.06 \pm 0.01^{\mathrm{A}, \mathrm{a}}$ & $0.07 \pm 0.01^{\mathrm{A}, \mathrm{a}}$ & $0.06 \pm 0.01^{\mathrm{A}, \mathrm{a}}$ \\
\hline Trilux $(\mathrm{T})$ & $0.09 \pm 0.02^{\mathrm{A}, \mathrm{a}}$ & $0.08 \pm 0.01^{\mathrm{A}, \mathrm{a}}$ & $0.09 \pm 0.02^{\mathrm{A}, \mathrm{a}}$ & $0.07 \pm 0.01^{\mathrm{A}, \mathrm{a}}$ & $0.07 \pm 0.01^{\mathrm{A}, \mathrm{a}}$ & $0.09 \pm 0.02^{\mathrm{A}, \mathrm{a}}$ \\
\hline
\end{tabular}

†Same uppercase letters represent values without significant statistical difference among treatments for each artificial tooth in each experimental acid period (before or after challenges) ( $p>0.05$ by ANOVA and Tukey-tests). Same lowercase letters represent values without significant statistical difference in each treatment for each artificial tooth before and after acid challenges ( $\mathrm{p}>0.05$ by paired $\mathrm{t}$-test). 


\section{Discussion}

This study evaluated the influence of corrosive treatments on color stability, Vickers hardness and surface roughness of artificial teeth. The null hypothesis was partially rejected because the color stability and hardness were influenced by acid treatments and immersion time in both acrylic resin teeth tested.

The color change of artificial teeth may be caused by intrinsic factors associated with chemical changes in the composition of the material, such as the difference between the type of inorganic material used; and extrinsic factors, which are related to the surface properties of the material and the environment in which it is inserted [6,18]. The cola-based drink is one of the extrinsic factors that may have an effect on the structure and the color of acrylic teeth [19], mainly because it damages the surface integrity of the material due to extremely low $\mathrm{pH}[19,20]$. In addition, the cola-based drinks contain caramel colors addictive, which is dark and may have a greater tendency to staining [20]. In the present study, cola drink was used in the acid challenges due to its high consumption by the population and because it has high erosive potential caused by its low $\mathrm{pH}$ and low concentration of calcium and fluoride [21].

The color stability in artificial denture teeth has already been evaluated in other studies [6,9,18] when immersed in different acid solutions. The immersion in cola drink promoted color change in artificial teeth and was dependent of the artificial teeth composition and the time of immersion in the beverage [6].

In the present study, there was higher color change for the Biotone group in the immersion treatment (BI) compared to the other treatments (BAC and BC) (Table 1), showing that the color change of artificial teeth is proportional to the immersion time in beverage. In the immersion group the samples remained more time in contact with cola drink compared to the acid challenge group, corroborating with previous studies [4]. Additionally, the Biotone immersion group (BI) showed higher color variation compared to the Trilux immersion group (TI) (Table 1). The distinct layers of acrylic artificial teeth are affected in different degrees of intensity according to the immersion solutions, with modifications in the resin interstitial matrix [22]. The color determination can be influenced by the color, clarity and surface thickness of the material; and when the thickness of the material increases, the luminosity of the acrylic resin becomes smaller [23].

The most significant color change of BI compared to TI group may be related to the greater thickness in the transversal sections of Biotone teeth, promoting lower translucency [24]. In addition, the color stability of TI group may be related to the lower presence of reagents in its composition, such as benzoyl peroxide, which after chemical cure reaction remains on the surface and generates deterioration of color [25]. Trilux teeth are composed of cross-linked polymethylmethacrylate (PMMA) chains with high molecular weight, combined with the double cross-linking system (DCL) [7] and three layers acrylic teeth (incisal, cervical and dentin), according to the manufacturer. These factors favor the crosslinking quality of polymer chains, improving its mechanical properties and reducing the tendency to form pre-cracks under masticatory stresses and the solubility in organic solvents [26]. Biotone artificial teeth are also composed by PMMA chains, but they have low molecular weight [8] and two layers of acrylic teeth (body and enamel), according to the manufacturer. This composition of Biotone group can also have contributed to low color stability, as also found in other study [18]. However, despite of the color variation obtained for both artificial teeth groups in the present study, the values found were lower than 3.3 and are clinically acceptable [17].

After treatments, there was significant reduction of VHN values for both artificial teeth, regardless of cola drink or artificial saliva immersion or challenge. Similar results were found in other studies [7,27,28], in which the hardness of the acrylic resin teeth was reduced after immersion in water. The acrylic polymers can absorb water that acts as a plasticizer and reduces the hardness of the material through the formation of 
microcracks caused by the absorption/adsorption process [29]. The hydrolytic degradation of the acrylic resin may lead to a gradual deterioration of the polymer structure over time, influencing its mechanical properties, dimensional stability and biocompatibility [29]. In this context, the plasticizing effect and the hydrolytic degradation may be related to the reduction of VHN values of acrylic teeth in the present study, regardless of the solution immersion and the composition of acrylic artificial teeth.

The surface roughness ( $\mathrm{Ra}$ ) of artificial teeth was more related to the microbial adhesion [13]. The smoother surface of denture teeth will result in highest longevity of prosthesis due to less microbial colonization [30]. However, in the literature, there are few reports that evaluated the surface roughness of acrylic teeth after corrosive challenge and immersion in acidic beverages. The present study showed that there was no significant difference for Ra values after acid treatments (Table 3). Similarly, other study [7] did not find alteration on roughness surface of artificial acrylic teeth after 15 and 30 days of immersion in acidic beverages. These results indicate that the effects of longer exposure times to acidic beverages on the surface roughness of acrylic artificial teeth should be further investigated. Additionally, a previous study [8] evaluated the roughness surface of artificial acrylic resin teeth before and after soaking in cola drink. There was only difference in Ra values where the abrasion by toothbrushing was performed before the immersion in cola drink. Thus, the toothbrushing may have acted as an abrasive factor on acrylic teeth surface, making them less irregular and influencing the surface roughness [8,30].

Despite the limitations of an in vitro study, the present results showed that the surface properties of acrylic resin artificial teeth, especially hardness and color surface, can be modified by the exposure of acid beverages. The immersion in cola drink caused higher color alteration than acid challenge, demonstrating that the exposure time of artificial teeth in acidic beverage and the time of remineralization in artificial saliva affected the color of the material. However, these results should be carefully evaluated, because in the oral cavity the artificial teeth are influenced by other factors that could interfere in their degradation, such as the presence of saliva, chemical and mechanical methods of cleaning the prosthesis, contact with opposing teeth and food, the presence of parafunctional habits and the different frequencies of intake of acidic foods among individuals. Thus, future in vitro and in vivo studies need to be conducted to evaluate these variables and the effect of acidic beverages on the properties of artificial teeth.

\section{Conclusion}

The hardness of acrylic resin teeth decreased after the acid challenges for 7 days, but the roughness surface was not changed. The color of resin teeth was more affected by the time of exposure in cola beverage and the time of remineralization in artificial saliva (continuous immersion), which were considered important factors associated to the material degradation surface.

\section{Authors' Contributions}

\begin{tabular}{|c|c|c|}
\hline LDG & (iD) $0000-0003-4979-043 \mathrm{X}$ & Investigation and Formal Analysis. \\
\hline TCM & (iD) $0000-0003-1920-1745$ & Investigation and Formal Analysis and Writing - Original Draft Preparation. \\
\hline AGL & (iD) $0000-0001-6163-0004$ & Investigation and Formal Analysis and Writing - Original Draft Preparation. \\
\hline MIBA & (iD) $0000-0001-7885-5939$ & Investigation and Formal Analysis and Writing - Original Draft Preparation. \\
\hline HLC & (iD) $0000-0002-5111-7781$ & Conceptualization, Formal Analysis and Writing - Review and Editing. \\
\hline TSB & (iD) $0000-0002-3479-7789$ & Writing - Original Draft Preparation and Writing - Review and Editing. \\
\hline FGC & (iD) $0000-0003-2510-1329$ & $\begin{array}{l}\text { Conceptualization, Methodology, Formal Analysis, Writing - Original Draft } \\
\text { Preparation and Writing - Review and Editing. }\end{array}$ \\
\hline
\end{tabular}




\section{Financial Support}

None.

\section{Conflict of Interest}

The authors declare no conflicts of interest.

\section{References}

[1] Heintze SD, Monreal D, Rousson V. Fatigue resistance of denture teeth. J Mech Behav Biomed Mater 2016; 53:37383. https://doi.org/10.1016/j.jmbbm.2015.08.034

[2] Wagner B, Kern M. Clinical evaluation of removable partial dentures 10 years after insertion: success rates, hygienic problems, and technical failures. Clin Oral Investig 2000; 4(2):74-80. https://doi.org/10.1007/s007840050119

[3] Stober T, Geiger A, Rues S, Dreyhaupt J, Rammelsberg P, Ohlmann B. Factors affecting wear of composite resin denture teeth-24-month results from a clinical study. Clin Oral Investig 2012; 16(2):413-20. https://doi.org/10.1007/s00784-011-0534-y

[4] Hipólito AC, Barão VA, Faverani LP, Ferreira MB, Assunção WG. Color degradation of acrylic resin denture teeth as a function of liquid diet: ultraviolet-visible reflection analysis. J Biomed Opt 2013; 18(10):105005. https://doi.org/10.1117/1.JBO.18.10.105005

[5] Preis V, Hahnel S, Behr M, Rosentritt M. Contact wear of artificial denture teeth. J Prosthodont Res 2018; 62(2):2527. https://doi.org/10.1016/j.jpor.2017.11.001

[6] Koksal T, Dikbas I. Color stability of different denture teeth materials against various staining agents. Dent Mater J 2008; 27(1):139-44. https://doi.org/10.4012/dmj.27.139

[7] Neppelenbroek KH, Kuroishi E, Hotta J, Marques VR, Moffa EB, Soares S, et al. Surface properties of multilayered, acrylic resin artificial teeth after immersion in staining beverages. J Appl Oral Sci 2015; 23(4):376-82. https://doi.org/10.1590/1678-775720150054

[8] Pero AC, Borghi I, Marin DOM, Policastro VB, Junior NMO, Compagnoni MA. Physical properties of acrylic resin teeth submitted to toothbrushing and immersion in beverages. Eur J Gen Dent 2016; 5(3):122-6. https://doi.org/10.4103/2278-9626.189257

[9] Waldemarin RF, Terra PC, Pinto LR, Faot F, Camacho GB. Color change in acrylic resin processed in three ways after immersion in water, cola, coffee, mate and wine. Acta Odontol Latinoam 2013; 26(3):138-43.

[10] Shellis RP, Addy M. The interactions between attrition, abrasion and erosion in tooth wear. Monogr Oral Sci 2014; 25:32-45. https://doi.org/10.1159/000359936

[11] Lussi A, Carvalho TS. Erosive tooth wear: a multifactorial condition of growing concern and increasing knowledge. Monogr Oral Sci 2014; 25:1-15. https://doi.org/10.1159/000360380

[12] Policastro VB, Giro G, Leite AR, Mendoza-Marin DO, Paleari AG, Compagnoni MA, et al. In vitro assessment of the abrasion resistance of two types of artificial teeth submitted to brushing. J Prosthodont 2016; 25(6):485-8. https://doi.org/10.1111/jopr.12455

[13] Barreto JO, de Alencar-Silva FJ, Oliveira VC, Silva-Lovato CH, Silva PG, Regis RR. The effect of a continuous mechanical polishing protocol on surface roughness, biofilm adhesion, and color stability of acrylic resin artificial teeth. J Prosthodont 2019; 28(1):e110-e117. https://doi.org/10.1111/jopr.12925

[14] Amaechi BT, Higham SM, Edgar WM. Techniques for the production of dental eroded lesions in vitro. J Oral Rehabil 1999; 26(2):97-102. https://doi.org/10.1046/j.1365-2842.1999.00349.x

[15] Magalhães AC, Levy FM, Rios D, Buzalaf MA. Effect of a single application of TiF4 and NaF varnishes and solutions on dentin erosion in vitro. J Dent 2010; 38(2):153-7. https://doi.org/10.1016/j.jdent.2009.09.015

[16] Gondim BLC, Medeiros IC, Costa BP, Carlo HL, Santos RL, Carvalho FG. Effects of erosive challenge on the morphology and surface properties of luting cements. Rev Odontol UNESP 2016; 45(2):103-9. https://doi.org/10.1590/1807-2577.022315

[17] Um CM, Ruyter IE. E. Staining of resin-based veneering materials with coffee and tea. Quintessence Int 1991; 22(5):377-86.

[18] Mutlu-Sagesen L, Ergün G, Ozkan Y, Bek B. Color stability of different denture teeth materials: an in vitro study. J Oral Sci 2001; 43(3):193-205. https://doi.org/10.2334/josnusd.43.193

[19] Leite VM, Pisani MX, Paranhos HFO, Souza RF, Lovato CHS. Effect of ageing and immersion in different beverages on properties of denture lining materials. J Appl Oral Sci 2010; 18(4):372-8. https://doi.org/10.1590/s1678-77572010000400009

[20] Mousavi S, Narimani S, Hekmatfar S, Jafari K. Colour stability of various types of acrylic teeth exposed to coffee, tea and cola. J Dent Biomater 2016; 3(4):335-40.

[21] Lussi A, Jaeggi T, Zero D. The role of diet in the aetiology of dental erosion. Caries Res 2004; 38(Suppl 1):34-44. https://doi.org/10.1159/000074360 
[22] Robinson JG, McCabe JF, Storer R. The whitening of acrylic dentures: the role of denture cleansers. Br Dent J 1985; 159(8):247-50. https://doi.org/10.1038/sj.bdj.4805694

[23] Kanie T, Arikawa H, Fujii K, Inoue K. Physical and mechanical properties of PMMA resins containing gammamethacryloxypropyltrimethoxysilane. J Oral Rehabil 2004; 31(2):166-71.

https://doi.org/10.1111/j.1365-2842.2004.01043.x

[24] Liberman R, Combe EC, Piddock V, Watts DC. Colour changes in acrylic teeth - comparisonof an objective and subjective method. J Oral Rehabil 1996; 23(7):464-9. https://doi.org/10.1111/j.1365-2842.1996.tbo0880.x

[25] Assunção WG, Barão VA, Pita MS, Goiato MC. Effect of polymerization methods and thermal cycling on color stability of acrylic resin denture teeth. J Prosthet Dent 2009; 102(6):385-92.

https://doi.org/10.1016/So022-3913(09)60200-6

[26] Kurtulmus-Yilmaz S, Deniz ST. Evaluation of staining susceptibility of resin artificial teeth and stain removal efficacy of denture cleansers. Acta Odontol Scand 2014; 72(8):811-8. https://doi.org/10.3109/00016357.2014.913195

[27] Campanha NH, Pavarina AC, Vergani CE, Machado AL. Effect of microwave sterelization and water storage on the vickers hardness of acrylic resin denture teeth. J Prosthet Dent 2005; 93(5):483-7. https://doi.org/10.1016/j.prosdent.2005.02.016

[28] Pavarina AC, Vergani CE, Machado AL, Giampaolo ET, Teraoka MT. The effect of the disinfectant solutions on the hardness of acrylic resin denture teeth. J Oral Rehabil 2003; 30(7):749-52.

https://doi.org/10.1046/j.1365-2842.2003.01145.x

[29] Ferracane JL. Hygroscopic and hydrolytic effects in dental polymer networks. Dent Mater 2006; 22(3):211-22. https://doi.org/10.1016/j.dental.2005.05.005

[30] Ayaz EA, Altintas SH, Turgut S. Effects of cigarette smoke and denture cleaners on the surface roughness and color stability of different denture teeth. J Prosthet Dent 2014; 112(2):241-8. https://doi.org/10.1016/j.prosdent.2014.01.027 